brazilianpoliticalsciencereview

BOOK REVIEW

\title{
Finally Together: Democracy and Reduction in Inequality in Latin America*
}

\author{
by Pedro Floriano Ribeiro \\ Universidade Federal de São Carlos, Brazil
}

(HUBER, Evelyne and STEPHENS, John D. Democracy and the Left: Social Policy and Inequality in Latin America. Chicago: University of Chicago Press, 2012).

uring the last quarter of the $20^{\text {th }}$ century the research agenda for
comparative studies of Latin America concentrated on the debate over processes of overthrowing authoritarian regimes and that of building new democratic systems. With the transitions completed, this "transitionology" field began to focus on other concerns and objectives. In the $21^{\text {st }}$ century, Latin Americanists began to emphasize themes such as quality and the consolidation of democratic regimes, the institutionalization of party systems (with indicators that in both cases would reveal fragilities even in the most "consolidated" cases), innovations and difficulties in terms of public policies and the experience of governance, problems in making effective the practice of citizenship, and limitations in combatting historical problems of inequality and poverty.

The red (or pink?) wave that swept over the continent during the first decade of this century, with the rise to power of leftist parties and movements in various countries, also received particular attention in this literature, drastically increasing studies on the topic. A glance at Amazon.com using the search phrase "left in Latin America" returns dozens of titles, with an emphasis on (sometimes rough) comparisons between the democratic and moderate left (such as the Workers' Party in Brazil and the Socialist Party in Chile) and the more radical forces with questionable tendencies in regard to democracy (as in Venezuela). 
Within this context, it once again became fashionable to discuss populism, a topic that had been little discussed in recent years. For some, this is a typically Latin American phenomenon that seems to foster a type of folklore mindset about the region, while retaining parallels with the literary magical realism of the 1960's. For others, it would be more precise to focus on something typically about Latin Americans, given that phenomena such as Berlusconi and Beppe Grillo in Italy, or the National Front of the Le Pen family in France, prove that demagogic appeals, direct links with the masses, and disdain for institutions are not outcomes native and exclusive to the region.

In any case, this boom in comparative studies of Latin American left has its high points that have contributed to a deeper understanding of the politics in the region. The books organized by Mainwaring and Scully (2009), Weyland, Madrid and Hunter (2010) and Levitsky and Roberts (2011) are among the most important references of recent years that manage to avoid stereotypes about the region through competent and empirically based research. To them we may add the book by Evelyne Huber and John D. Stephens, (professors at the University of North Carolina, Chapel Hill), published in 2012. In contrast to the other works cited above, Democracy and the Left: Social Policy and Inequality in Latin America is not an edited volume, which means that it does not suffer from the problems of imbalance and heterogeneity in terms of analytical quality and empirical effort that often impede building a general panorama and comparing among countries studied by different authors (even when the editors try to maintain uniform theoretical focuses, strategies, and frameworks). However, in spite of the "Left" in the title, one should not reduce the study to just another of many contributions about the red wave in Latin America. In fact, the book focuses on the links and long-term effects between democracy, redistributive policies, poverty, and inequality in the region, with forces of the left acting as an intervening variable in this relation. Working with these principal variables, the authors develop an impressive work that is theoretically consistent, exhaustive in terms of data collected, and methodologically sophisticated, combining the solid use of statistical tools with a comparative historical analysis of selected cases. As far as I know, it is the most competent and complete work that manages to establish not only statistical but also causal links between the consolidation of democracy, 
redistributive policies (within the context of the construction of a welfare state), and the reduction in inequality and poverty in Latin America. It is an obligatory text for students of the region as well as for those who study these topics in different contexts-such as the extensive European literature about the construction (and reform) of welfare states. In addition, the book comments on the broader discussion about the potential of democracy in the $21^{\text {st }}$ century and its impact on the everyday lives of people.

In theoretical terms as well as in regard to the methods used, Huber and Stephens achieve great success in applying to Latin America theories and concepts consecrated in the literature focusing on other regions. This is a considerable achievement, given that the authors forego the use of concepts supposedly exclusive to the region (clientelism, populism, etc) to explain the phenomena being studied. Democratic consolidation in much of the region and the difficulties confronted by older democracies (Western Europe and the USA) have demanded that the more recently democratized countries no longer be seen as "exotic" cases, a demand that the authors certainly fulfill. They adapt analytical models and instruments developed by themselves in a number of previous studies on the development of the welfare state in advanced capitalist countries (HUBER and STEPHENS, 2001).

This study primarily aims to identify the principal variables that explain the differences in terms of redistributive social policies and economic inequality, comparing both Latin American countries as well as those in same country over time. On the theoretical plane, the authors address this challenge by applying the power constellations theory model, which was previously used (HUBER and STEPHENS, 2001). The model delimits three clusters of power as fundamental variables to explain the regime of social policies:

1) The correlation of power within the country between social classes and political parties. In this cluster, they emphasize the different social structure and the late advance of working class organizations (unionism and leftist parties) when compared to the European historical process. This is the central explanatory factor (at times, the only) in much of the literature about the European welfare state, such as the power resources theory, that underlines the importance of social democracy and the union movement for the advance of social policies. Contrary to 
the economic policy literature founded on the framework of rational choice by Meltzer and Richard (1981), the power resources theory associates high rates of economic inequality with the concentration of power resources, which would impede the construction of redistributive policies and tax systems. One of the central challenges of the authors thus becomes finding a way to explain the manner in which some of the most unequal countries on the planet were able to develop redistributive policies, and thus to decrease socio-economic inequality.

2) The structure of the state and society-state relations. While studies of wealthy countries focused on the multiplication of veto points able to block reforms in social policies (whether in terms of their enlargement or reduction), in the Latin American reality the autonomy of the State vis-à-vis society and its ability to collect taxes and to implement policies become relevant variables.

3) Transnational power structures that predominantly include the relations and forms of insertion of the country into the international economy and the role of international organizations. Once again, what was not a relevant issue in regard to developed countries-at least until the consolidation of the European Union-merits greater attention within the context of external dependence, agricultural export economies, and frequent loans to balance accounts, etc. Thus, the roles of the International Monetary Fund, the World Bank, and the Washington Consensus appear as part of the explanation, principally for the neoliberal reforms at the end of the $20^{\text {th }}$ century.

In transposing theoretical-analytic models to be used in reference to Latin America, perhaps the most important adaptation adopted by the authors (above all for the first two clusters) has been in regard to democracy, which changes from a constant, in the analyses of advanced capitalist countries in the post-WWII period, to an independent variable in the research design. In this manner, it is able to influence the comparison between countries and within the same country. The operationalization of the power constellations theory for empirical analysis involves two planes. On the quantitative plane, they apply various statistical tools for comparing 18 Latin American countries (Cuba and Haiti are excluded), mobilizing political variables (years of democracy, force of leftist parties, etc), and social and economic variables to understand the construction of the welfare state and the struggle against poverty and economic inequality in the region. This 
strategy is divided into two parts. In the first one (Chapter 4), the authors analyze the formative period of welfare states, characterized by a development based on the import substitution industrialization model that continued until around 1980. The data suggest that the size of the urban working class and the number of years of democracy are the principal explanatory variables in the national effort in terms of social policies (considering both the volume of expenditures as well as coverage). Five welfare state leaders emerge from this comparison: Brazil, Argentina, Chile, Uruguay, and Costa Rica.

With more complete and reliable data, the second period spans 1970 to 2006 (Chapter 5). This includes, therefore, the external debt and hyperinflation crisis of the 1980s, the peak of neoliberal policies that impacted social expenditures in the 1990s, under the direct influence of the Washington Consensus, and the beginning of the shift to the left that reverted, at least partially, the restrictive policies of that time. Huber and Stephens performed a pooled time series analysis to measure the effects of numerous variables not only on national social spending (education, health, social security) but also on the expected results of this spending; economic inequality and poverty were used as dependent variables. The analysis is convincing in indicating democracy as the principal explanatory variable for the reduction in poverty and inequality-not in the first years of redemocratization, but in the long term (around 20 years). In comparison to the "left variable", democracy shows itself to be a more significant factor, able to impact the dependent variables per se.

Although the time series analysis suggests causal relations among variables, the authors take much care to avoid confusing statistical association with causality. They use the quantitative analyses to verify whether a relation between the variables exists and to measure the robustness of these relations. Quantitative analysis is also the point of departure for the selection of cases that will be the targets of the qualitative analysis. The authors adopted a strategy of selecting most similar cases in terms of the dependent variable, and choosing five most successful countries in terms of the construction of their welfare states. The selection of only the most positive cases is an option that always triggers debate among comparative politics scholars. Huber and Stephens defend themselves with the argument that there is significant variation in terms of independent variables, 
which makes it possible to follow different historical processes that lead to similar results. The five countries are the topics of an in-depth comparative historical analysis (Chapters 4, 6, and 7) in which the authors, using secondary sources, trace the historical sequences of each country over almost all the 20th century. Thus, they establish links and causal mechanisms not only between the principal variables in the quantitative analysis but also between other variables, situations, and actors that are invisible in the statistical analyses. As with the advanced capitalist countries (HUBER and STEPHENS, 2001), the authors consider it essential to follow the long-term trajectories of social policies due to the high degrees of path dependence of these policies. This within-case analysis is successful, and points toward two patterns found in welfare state leaders: Chile, Uruguay, and Costa Rica took paths based on democracy and on the force of leftist parties and movements, while Brazil and Argentina experienced processes characterized by authoritarian cooptation of the urban working classes throughout the $20^{\text {th }}$ century.

The combination of quantitative analyses and historical comparison confirms democracy as the principal explanatory variable that influenced the reduction in poverty and inequality rates in the region. In part, there is a causal chain that indirectly links these variables. A democratic regime is a precondition for the organization and strengthening of leftist movements and parties (including labor union movements). The arrival of parties with more egalitarian agendas into the central government greatly influences redistributive policies, thus reducing poverty and inequality. However, the "leftist variable" does not have an influence as important as that of democracy itself, in a direct causal relation. Democracy fosters the strengthening of civil society and venues for protest and participation. Furthermore, it places elites under the electoral scrutiny of the population (which can make use of those forces of the left as an option). With the good old Schumpeterian mechanism in operation, social spending increases, which leads to a reduction in poverty and inequality rates. Therefore, although the transitions have not necessarily led to "quality" regimes (whatever that means), even democracies under consolidation or ones that are unstable are able to generate positive results for their population. 
The importance of the democratic factor is confirmed at the end of the book when the authors move from cross-national analysis to cross-regional analysis, comparing Portugal and Spain to countries of the Southern Cone (Chapter 7). Huber and Stephens do not search for the root of the problems in Brazil, Argentina, Chile, and Uruguay in the former colonizers. Rather, they seek to explain why the two regions, Iberia and the Southern Cone, which were similar in many ways between 1960 and 1970, became very different at the turn of the century. The selection method for historical comparison is now inverted: the authors begin with cases of similar profiles at the beginning of the trajectory, but which arrive at different results at the end. Around 1970, both Iberia and the Southern Cone had economies based on the import substitution industrialization model and their indicators were similar in terms of concentration of land holdings, socio-economic inequality, GDP per capita, economic development, and level of education. Their social welfare systems were also similar, both in terms of expenditure efforts as well as in regard to the Bismarckian regime (contributory and employment-based social system, which was stratified according to professional categories). Moreover, all of the countries were under dictatorial regimes-if not at that moment, then shortly thereafter. Less than 50 years later, Portugal and Spain were more similar to wealthy European countries than to their former colonies, even with the advances that the latter experienced (nevertheless, some problems in terms of social policies were still similar). The authors attribute this differentiation of trajectories to two factors: 1) Portugal and Spain became democratic before the Southern Cone countries, and also had leftist governments earlier (and for long periods); 2) the influence of the Washington Consensus led to cuts in the welfare state of the Southern Cone countries (above all in pension reforms), while the Iberian countries began to reflect the European Social Model.

Beyond its more specialized discussion, the book also contributes to the debate about parties and party systems in the region. The arrival to governmental power of leftist parties directly influences social policies and the struggle against inequality due to income transfer programs, the expansion of public services of education and health, subsidy policies, etc. Moreover, the conclusions suggest that the positioning of parties on an ideological scale possesses some consistency: parties of the left, center, and right choose different options when they govern, 
which generates concrete results that are also discernable. This finding (which repeats the classical analyses about the role of the European left in the development of the welfare state) is a strong argument against part of the literature that has insisted on the thesis of the ideological indifferentiation of Latin American parties.

However, the principal contribution of Huber and Stephens is, in my view, the proof they provide of the long-term connections between democracy and the reduction of poverty and inequality. With this, they confirm the findings of other authors who write about Latin America (SEGURA-UBIERGO, 2007) and about other regions (HAGGARD and KAUFMAN, 2008; McGUIRE, 2010). Nevertheless, the debate is still far from arriving at a consensus. In a recent book, Przeworski (2010) notes that one should not demand from democracy anything that it does not promise to deliver. Comparing data from around the world, the author concludes that democracies do not make a difference in terms of the reduction in inequality, when compared to authoritarian regimes-a conclusion similar to that of Ross (2006). The post-communist countries, for example, show that the transition to democracy can bring more poverty and inequality, rather than less. In fact, the transition to democracy, beginning from an authoritarian/egalitarian context (Eastern Europe and the Soviet Union) will lead to different relative trajectories in indicators of inequality when compared to redemocratization processes that have dictatorships with extreme social inequality as points of departure (Latin America). In the words of Hubert and Stephens (p.12), "Democracy does not guarantee uniform movement toward lower poverty and inequality, but it makes gradual movement in this direction possible". Whether due to permitting the ascension of parties concerned with social justice, or to the repeated functioning, during decades, of the Schumpeterian mechanisms of the electoral selection of elites minimally concerned with the well-being of the population, democracy makes a difference. For those who are dissatisfied with it (and they are not few), this is quite a discovery.

Translated by Cabo Verde 


\section{References}

HAGGARD, Stephan and KAUFMAN, Robert R. (2008), Development, Democracy, and Welfare States: Latin America, East Asia, and Eastern Europe. Princeton: Princeton University Press.

HUBER, Evelyne and STEPHENS, John D. (2001), Development and Crisis of the Welfare State: Parties and Policies in Global Markets. Chicago: University of Chicago Press.

LEVITSKY, Steven and ROBERTS, Kenneth M. (eds.) (2011), The Resurgence of the Latin American Left. Baltimore: Johns Hopkins University Press.

MAINWARING, Scott and SCULLY, Timothy (eds.) (2009), Democratic Governance in Latin America. Stanford: Stanford University Press.

MCGUIRE, James W. (2010), Wealth, Health, and Democracy in East Asia and Latin America. New York: Cambridge University Press.

MELTZER, Allan H. and RICHARD, Scott F. (1981), A Rational Theory of the Size of Government. The Journal of Political Economy. Vol. 89, № 05, pp. 914-927.

PRZEWORSKI, Adam (2010), Democracy and the Limits of Self-Government. New York: Cambridge University Press.

ROSS, Michael (2006), Is Democracy Good for the Poor? American Journal of Political Science. Vol. 50, № 04, pp. 860-874.

SEGURA-UBIERGO, Alex (2007), The Political Economy of the Welfare State in Latin America: Globalization, Democracy, and Development. New York: Cambridge University Press.

WEYLAND, Kurt; MADRID, Raúl and HUNTER, Wendy (eds.) (2010), Leftist Governments in Latin America: Successes and Shortcomings. New York: Cambridge University Press. 